\title{
A Resident-led Initiative Improves Screening and Treatment for Vitamin D Deficiency in Patients with Hip Fractures
}

\author{
Drew A. Lansdown MD, Amanda Whitaker MD, Rosanna Wustrack MD, \\ Aenor Sawyer MD, Erik N. Hansen MD
}

Received: 8 April 2016/ Accepted: 10 August 2016/Published online: 22 August 2016

(C) The Association of Bone and Joint Surgeons \& 2016

\begin{abstract}
Background Acute hip fractures carry a high risk of morbidity and are associated with low vitamin D levels. Improvements in screening and treating low vitamin D levels may lead to lower fall rates and a lower likelihood of additional fragility fractures. However, patients with low vitamin D levels often remain unassessed and untreated, even after they experience these fractures.

Questions/purposes We wished to determine whether a resident-led initiative can improve (1) screening for and (2) treatment of vitamin D deficiency in patients with acute hip fractures.

Methods Our department initiated a housestaff-led, quality improvement project focused on screening and treating vitamin D deficiency in patients with acute hip fractures. Screening encompassed checking serum 25-hydroxyvitamin D level during the acute hospitalization, and treating was defined as starting supplementation before discharge when the serum 25-hydroxyvitamin D level was
\end{abstract}

Each author certifies that he or she has no commercial associations (eg, consultancies, stock ownership, equity interest, patent/licensing arrangements, etc) that might pose a conflict of interest in connection with the submitted article.

All ICMJE Conflict of Interest Forms for authors and Clinical Orthopaedics and Related Research ${ }^{\circledR}$ editors and board members are on file with the publication and can be viewed on request.

Each author certifies that his or her institution approved the human protocol for this investigation, that all investigations were conducted in conformity with ethical principles of research, and that informed consent for participation in the study was obtained.

D. A. Lansdown, A. Whitaker, R. Wustrack, A. Sawyer,

E. N. Hansen $(\square)$

Department of Orthopaedic Surgery, University of California,

San Francisco, 500 Parnassus Ave MU320W, Box 0728,

San Francisco, CA 94143, USA

e-mail: Erik.hansen@ucsf.edu; erik.hansen415@gmail.com less than $30 \mathrm{ng} / \mathrm{mL}$. To evaluate the efficacy of this program, an administrative database identified 283 patients treated surgically for an acute hip fracture between July 2010 and June 2014. This period included 2 years before program initiation (Year $1, \mathrm{n}=65$ patients; Year 2, $\mathrm{n}=61$ patients), the initial program year (Year 3, n = 66 patients), and the subsequent program year (Year $4, \mathrm{n}=91$ patients). Followup was extended to 6 weeks after treatment with $9.2 \%(26 / 282)$ of patients lost to followup. Eight patients were excluded owing to documented intolerance of vitamin D supplementation. There were no differences regarding patient demographics, fracture type, or treatment rendered across these 4 years. The primary endpoints were the proportion of patients screened and treated for vitamin D deficiency. The secondary endpoint was the continuation of vitamin D supplementation at the patient's 6 week followup, according to the patient's medication list at that visit. This analysis included all patients, assuming those lost to followup had not continued supplementation. ANOVA and chi-square tests were used to evaluate the differences in demographic data and in screening and treating rates.

Results Screening for vitamin D deficiency improved after initiation of the resident-led quality improvement program, with screening performed for $31 \%$ of patients in Year 1 (20/65; odds ratio [OR], 0.44; 95\% CI, 0.26-0.75), $20 \%$ of patients in Year 2 (12/61; OR, 0.24; 95\% CI, 0.13$0.46), 46 \%$ of patients in Year 3 (30/66; OR, 0.83; 95\% CI, $0.51-1.35)$, and $88 \%$ of patients in Year 4 (80/91; OR, 7.27; 95\% CI, 3.87-13.7) ( $\mathrm{p}<0.001$ ). Vitamin D supplementation was initiated for $33 \%$ of patients in Year 1 (21/ 63; OR, 0.5; 95\% CI, 0.30-0.84), 28\% in Year 2 (17/61; OR, 0.39; 95\% CI, 0.22-0.68), 50\% in Year $3(32 / 64$; OR, 1.00; 95\% CI, 0.61-1.63), and 76\% in Year 4 (65/86; OR, 3.10; 95\% CI, 1.89-5.06) (p < 0.001). At early 
postoperative followup, we saw substantial improvement in the proportion of patients who continued receiving vitamin D supplementation: Year 1, $12 \%$ (8/64; OR, 0.14; 95\% CI, 0.07-0.30); Year 2, 15\% (9/61; OR, 0.17; 95\% CI, 0.09$0.35)$; Year 3, 26\% (16/64; OR, 0.33; 95\% CI, 0.19-0.59); and Year 4, 46\% (40/86; OR, 0.87; 95\% CI, 0.57-1.33) $(\mathrm{p}<0.001)$.

Conclusions Implementation of a resident-led quality improvement program resulted in higher rates of screening and treating vitamin D deficiency for patients with acute hip fractures. Housestaff-based initiatives may be an effective way to improve care processes that target improvements in bone health.

\section{Introduction}

As many as $20 \%$ of patients who experience an osteoporotic hip fracture will die within the first year of injury [12]. Furthermore, after sustaining one fragility fracture, patients have an $86 \%$ increased chance of sustaining another fragility fracture if osteoporosis goes untreated [10]. Low serum 25-hydroxyvitamin D2 (vitamin D) levels, with insufficiency defined as less than $30 \mathrm{ng} / \mathrm{mL}$ and deficiency as less than $20 \mathrm{ng} / \mathrm{mL}$, are associated with osteopenia, osteoporosis, and an elevated risk of sustaining a fracture [9]. The American Orthopaedic Association (AOA) produced a position statement in 2005 entitled "Own the Bone" emphasizing the need for orthopaedic surgeons to be champions for quality improvement surrounding bone health [2]. This comprehensive program includes increasing communication between specialists and primary providers, creating multidisciplinary teams surrounding bone health, and increasing screening and treatment for osteoporosis [18]. Orthopaedic surgery residents can play a critical role in effectively realizing the goals of the "Own the Bone" initiative by properly recognizing fragility fractures, obtaining appropriate history of fracture risk and poor bone quality, and providing appropriate recommendations for ongoing bone health treatment at the time of patient discharge.

Although the importance of vitamin D and calcium supplementation has been highlighted, hypovitaminosis D remains an overlooked and untreated problem in clinical practice [6]. There is no clear optimal protocol for ensuring appropriate in-hospital and postdischarge treatment of low vitamin D levels [7]. Various other medical specialties, including internal medicine, radiology, and neurosurgery, have shown efficacy of resident-led quality improvement programs [3, 8, 19]. Additionally, the Accreditation Council for Graduate Medical Education (ACGME) has placed an emphasis on trainees learning systems-based practices [1]. There has been interest in encouraging resident-based quality improvement projects as a way of satisfying this aspect of graduate medical education [16]. Residents are often the first orthopaedic surgery providers to treat patients with acute hip fractures at academic medical centers, and therefore are excellent candidates for implementing any changes in the care of this group of patients.

We therefore asked: (1) Would a resident-led quality improvement project result in improvement in the proportion of patients with acute hip fractures screened and treated for low vitamin D levels? (2) Would vitamin D supplementation be continued during the early postoperative period after hospital discharge?

\section{Methods}

After obtaining institutional review board approval for this study, a retrospective review of medical records was performed from July 1, 2010 to June 30, 2014 at a large quaternary care academic medical center. An administrative database identified 339 patients who were treated, and who had Current Procedural Terminology codes corresponding to a diagnosis of a hip fracture $(733.14,820$, $820.02,820.03,820.09,820.2,820.21,820.22,820.31$, and 820.8 ). We included patients older than 50 years with a surgically treated, acute femoral neck or intertrochanteric hip fracture. Patients were excluded if an injury was treated nonoperatively, if the injury was attributable to primary or metastatic cancer, or there was a chronic fracture or nonunion. There were eight patients with documented intolerance that precluded them from receiving vitamin D supplementation, and these patients were excluded from the analysis for treatment proportions. Two hundred eighty-three patients met the inclusion criteria during the 4 years of this study period, with 65 patients in Year 1 (July 1, 2010 to June 30, 2011), 61 in Year 2 (July 1, 2011 to June 30, 2012), 66 in Year 3 (July 1, 2012 to June 30, 2013), and 91 in Year 4 (July 1, 2013 to June 30, 2014). There were no differences in the mean ages, height, weight, BMI, race, or sex across the 4 years studied (Table 1).

We reviewed and recorded medical comorbidities for all patients (Table 2). Relevant medical conditions included a history of tobacco use (defined as a prior history of at least five pack-years), alcohol use (more than two drinks per day), fall history, neurocognitive disorders (ie, dementia, movement disorders, previous cerebrovascular accidents), an established diagnosis of osteoporosis, history of bisphosphonate use, and prior history of fractures. The fracture pattern, American Society of Anesthesiologists classification, and method of surgical treatment were recorded. There were no differences for history of smoking, 
Table 1. Demographics

\begin{tabular}{|c|c|c|c|c|c|}
\hline Demographic & 2010-2011 & 2011-2012 & $2012-2013$ & 2013-2014 & $\mathrm{p}$ Value \\
\hline Age in years & 80 & 77 & 80 & 78 & 0.530 \\
\hline (SD) & (11) & (11) & (12) & (12) & \\
\hline $\mathrm{BMI}$ in $\mathrm{kg} / \mathrm{m}^{2}$ & 24 & 25 & 24 & 24 & 0.313 \\
\hline (SD) & (5) & (4) & (5) & (5) & \\
\hline Median length of stay (days) & 5 & 5 & 5 & 4 & 0.356 \\
\hline Female patients $(\%)$ & $\begin{array}{l}45 \\
(69 \%)\end{array}$ & $\begin{array}{l}37 \\
(61 \%)\end{array}$ & $\begin{array}{l}40 \\
(61 \%)\end{array}$ & $\begin{array}{l}65 \\
(71 \%)\end{array}$ & 0.372 \\
\hline \multicolumn{6}{|l|}{ Race/ethnicity } \\
\hline Caucasian $(\%)$ & $\begin{array}{l}43 \\
(66 \%)\end{array}$ & $\begin{array}{l}36 \\
(59 \%)\end{array}$ & $\begin{array}{l}39 \\
(59 \%)\end{array}$ & $\begin{array}{l}57 \\
(63 \%)\end{array}$ & \\
\hline Asian (\%) & $\begin{array}{l}19 \\
(29 \%)\end{array}$ & $\begin{array}{l}16 \\
(26 \%)\end{array}$ & $\begin{array}{l}15 \\
(23 \%)\end{array}$ & $\begin{array}{l}23 \\
(25 \%)\end{array}$ & \\
\hline Hispanic (\%) & $\begin{array}{l}2 \\
(3 \%)\end{array}$ & $\begin{array}{l}1 \\
(2 \%)\end{array}$ & $\begin{array}{l}2 \\
(3 \%)\end{array}$ & $\begin{array}{l}2 \\
(2 \%)\end{array}$ & \\
\hline Black $(\%)$ & $\begin{array}{l}1 \\
(2 \%)\end{array}$ & $\begin{array}{l}3 \\
(5 \%)\end{array}$ & $\begin{array}{l}6 \\
(8 \%)\end{array}$ & $\begin{array}{l}1 \\
(1 \%)\end{array}$ & \\
\hline Other $(\%)$ & 0 & $\begin{array}{l}5 \\
(8 \%)\end{array}$ & $\begin{array}{l}6 \\
(8 \%)\end{array}$ & $\begin{array}{l}8 \\
(9 \%)\end{array}$ & 0.415 \\
\hline
\end{tabular}

Table 2. Medical comorbidities

\begin{tabular}{|c|c|c|c|c|c|}
\hline & 2010-2011 & 2011-2012 & 2012-2013 & 2013-2014 & $\mathrm{p}$ Value \\
\hline \multicolumn{6}{|l|}{ ASA classification } \\
\hline 1 & $1(2 \%)$ & 0 & 0 & 0 & \\
\hline 2 & $13(21 \%)$ & $16(30 \%)$ & $13(20 \%)$ & $26(29 \%)$ & \\
\hline 3 & $43(71 \%)$ & $34(63 \%)$ & $43(65 \%)$ & $52(57 \%)$ & \\
\hline 4 & $4(7 \%)$ & $3(6 \%)$ & $9(14 \%)$ & $13(14 \%)$ & \\
\hline 5 & 0 & $1(2 \%)$ & $1(2 \%)$ & 0 & 0.364 \\
\hline Smoking history & $21(32 \%)$ & $16(26 \%)$ & $25(38 \%)$ & $26(29 \%)$ & 0.492 \\
\hline Alcohol history & $12(19 \%)$ & $13(21 \%)$ & $15(23 \%)$ & $13(14 \%)$ & 0.543 \\
\hline Neurocognitive disorders & $23(35 \%)$ & $14(23 \%)$ & $33(50 \%)$ & $25(28 \%)$ & 0.005 \\
\hline Diagnosis of osteoporosis & $14(22 \%)$ & $9(15 \%)$ & $14(21 \%)$ & $26(29 \%)$ & 0.247 \\
\hline Bisphosphonates & $7(11 \%)$ & $6(10 \%)$ & $9(14 \%)$ & $12(13 \%)$ & 0.885 \\
\hline Previous fractures & $9(19 \%)$ & $14(23 \%)$ & $20(31 \%)$ & $32(35 \%)$ & 0.161 \\
\hline
\end{tabular}

history of alcohol use, diagnosis of osteoporosis, previous use of bisphosphonates, or previous history of fractures for the 4 years analyzed. The percentage of patients with neurocognitive disorders differed by year, with the highest proportion observed in Year 3 (50\% of patients; $p=0.005)$. Fracture patterns differed slightly across years, with a higher proportion of femoral neck fractures in Year 1 (49\%; $p=0.040)$, but there were no differences in treatment type across the 4 years (Table 3 ). With the numbers available, the mean vitamin D levels for screened patients were no different by year : Year $1,19.42 \pm 12.1 \mathrm{ng} / \mathrm{mL}$; Year 2, $18.33 \pm 6.1 \mathrm{ng} / \mathrm{mL}$; Year 3, $23.60 \pm 11.6 \mathrm{ng} / \mathrm{mL}$;
Year 4, 24.56 $\pm 10.1 \mathrm{ng} / \mathrm{mL}(\mathrm{p}=0.12)$. Of the patients who were screened for vitamin D deficiency, the prevalence of vitamin D insufficiency was no different by year: Year 1, $35 \%$ with normal levels (7/20; 95\% CI, 15\%-59\%) and $65 \%$ with insufficiency $(13 / 20 ; 95 \%$ CI, 40.8\%-84.6\%); Year 2, no patients with normal levels $(0 / 12$; 95\% CI, 0\%$27 \%$ ) and $100 \%$ with insufficiency $(12 / 12,97.5 \% \mathrm{CI}$, $73.5 \%-100 \%)$; Year 3, 23\% with normal levels $(7 / 30 ; 95 \%$ CI, $10 \%-42 \%)$ and $77 \%$ with insufficiency $(23 / 30 ; 95 \%$ CI, $58 \%-90 \%)$; Year 4, 29\% with normal levels (23/80; $95 \%$ CI, 19\%-40\%) and 71\% with insufficiency (57/80; 95\% CI, $60 \%-81 \%)(\mathrm{p}=0.14)$. 
Table 3. Fracture types and procedures

\begin{tabular}{lllll}
\hline Variable & $2010-2011$ & $2011-2012$ & $2012-2013$ & $2013-2014$ \\
\hline $\begin{array}{l}\text { Fracture type } \\
\text { Femoral neck }\end{array}$ & $32(49 \%)$ & $16(26 \%)$ & $22(33 \%)$ & $29(32 \%)$ \\
$\quad$ Intertrochanteric & $33(51 \%)$ & $45(74 \%)$ & $44(67 \%)$ & $62(68 \%)$ \\
Procedure & & & \\
Hemiarthroplasty & $21(32 \%)$ & $18(30 \%)$ & $22(33 \%)$ & $28(31 \%)$ \\
THA & $9(14 \%)$ & $8(13 \%)$ & $7(11 \%)$ & $6(7 \%)$ \\
Cephalomedullary nail & $15(23 \%)$ & $21(34 \%)$ & $24(36 \%)$ & $36(39 \%)$ \\
Sliding hip screw & $13(20 \%)$ & $6(10 \%)$ & $9(14 \%)$ & $6(8 \%)$ \\
Closed reduction percutaneous pinning & $6(9 \%)$ & $7(12 \%)$ & $3(5 \%)$ & $15(15 \%)$ \\
Open reduction internal fixation & $1(2 \%)$ & $1(2 \%)$ & $1(2 \%)$ & 0 \\
\hline
\end{tabular}

Housestaff Incentive Program

As part of a graduate medical education-led hospital-wide effort, our orthopaedic surgery residency program initiated a quality-improvement project. The hospital-wide Resident and Fellow Quality Improvement Incentive Program provides an opportunity for residents to develop quality or safety projects with defined measurable goals. An incentive of USD 400 per resident is provided at the conclusion of the year if the established goal is achieved.

In line with the national effort to improve the diagnosis and treatment of bone health in patients with fragility fractures, we selected screening and treating vitamin D deficiency and insufficiency as the goal of the quality improvement project. The specific goals established for this project were twofold: (1) to screen at least $70 \%$ of adult patients with acute hip fractures who were admitted for surgical treatment by checking the serum 25 -hydroxyvitamin $\mathrm{D}$ level, and (2) to initiate treatment with vitamin D supplementation in at least $70 \%$ of these patients when indicated (serum 25-hydroxyvitamin D level less than $30 \mathrm{ng} / \mathrm{mL}$ ).

To achieve these goals, we implemented a resident-led program to emphasize the importance of screening and treating vitamin D insufficiency in patients with hip fractures. Residents in all years of training in our institution's residency program participated in the initiative. Reminders were included as part of weekly e-mail communications, and announcements were made during weekly department meetings. An effort was made by the residents to review if patients had been appropriately screened for low vitamin D during morning fracture conference. Each quarter, the results of the initiative were tabulated and sent to all residents to provide feedback and positive encouragement on continued screening and treating low vitamin $\mathrm{D}$. The recommended treatment was 3000 IU of cholecalciferol (vitamin D3) per day, with the final supplementation protocol left to the discretion of the treatment team based on the patient's vitamin D level.

\section{Data Analysis}

After completion of the second year of this initiative (Year 4), data were reviewed to evaluate the effects of the program on the percentages of screening and treatment of low vitamin D levels in patients with hip fractures. This study was conceived after implementation of the quality improvement program to better determine its efficacy. Data from the 2 years before implementation of the program were used to establish a baseline and served as a historic control. The 2 years after starting this initiative were studied to evaluate program effectiveness. No other department-wide changes were made regarding the treatment practices for acute hip fractures in this time. We compared, by year, the percentage of patients who were screened, defined as having a vitamin D level checked during the acute hospitalization and including all patients with an acute hip fracture. We also compared, by year, the proportion of patients who were treated, defined as having vitamin D prescribed before discharge and including all patients except for those with a documented intolerance of vitamin D supplementation. As a secondary outcome, we compared, by year, the percentages of continued documentation of vitamin D supplementation at the patients' 6week followup with the denominator as all patients except for those with a documented intolerance of vitamin $D$ supplementation. There were 22 patients $(8 \%)$ who were lost to followup, but they were included in the analysis as not having supplementation at the 6-week followup.

We managed data in Excel ${ }^{\circledR}$ (Microsoft ${ }^{\circledR}$ Corporation, Redmond, WA, USA), and performed statistical analyses using Stata ${ }^{\circledR}$ (StataCorp, Austin, TX, USA). Comparisons were made between each of the 4 years. The means of continuous variables were compared using ANOVA tests with a Bonferroni correction. Categorical variables were compared using a chi-square test, and odds ratios (OR) with 95\% CIs were calculated for the primary endpoints. No attempts were made to estimate missing data points. 
Statistical significance was defined as a probability less than 0.05 .

\section{Results}

The proportion of patients screened after initiation of a resident-led quality improvement program improved substantially ( $<<0.001)$ (Fig. 1). Years 1 and 2 showed low rates of screening $(31 \%$ [20/65; OR, 0.44 ; 95\% CI, 0.260.75 ] and 20\% [12/61; OR, 0.24; 95\% CI, 0.13-0.46], respectively). Screening improved in Year 3 (46\%; 30/66; OR, 0.83; 95\% CI, 0.51-1.35) and showed the greatest improvement in Year $4(88 \%$; 80/91; OR, 7.27; 95\% CI, 3.87-13.7). With the numbers available, there was no difference in screening between sexes when comparing Years 1 and 2 (females screened: $29 \%$ [24/82; OR, 0.41; 95\% CI, $0.26-0.67]$ vs males screened: $18 \%$ [8/44; OR, $0.22 ; 95 \%$ CI, 0.10-0.48]; $\mathrm{p}=0.175$ ) with Years 3 and 4 (females screened: $71 \%$ [75/105; OR, 2.50; 95\% CI, 1.64-3.82] vs males screened: 67\% [35/52; OR, 2.06; 95\% CI, 1.153.68]; $\mathrm{p}=0.597)$. Treatment rates increased after the inception of this program $(\mathrm{p}<0.001)$ (Fig. 2). These rates were lowest in Years 1 and 2 (33\% [21/63; OR, 0.5; 95\% CI, 0.30-0.84] and 28\% [17/61; OR, 0.39; 95\% CI, 0.22$0.86])$. In Year 3, 50\% (32/64; OR, 1.00; 95\% CI, 0.611.63) of patients were treated for vitamin $D$ deficiency or insufficiency, and this rate improved to 76\% (65/86; OR, 3.10; 95\% CI, 1.89-5.06) in Year 4. There was a sex-based difference in treatment rates before the program started,

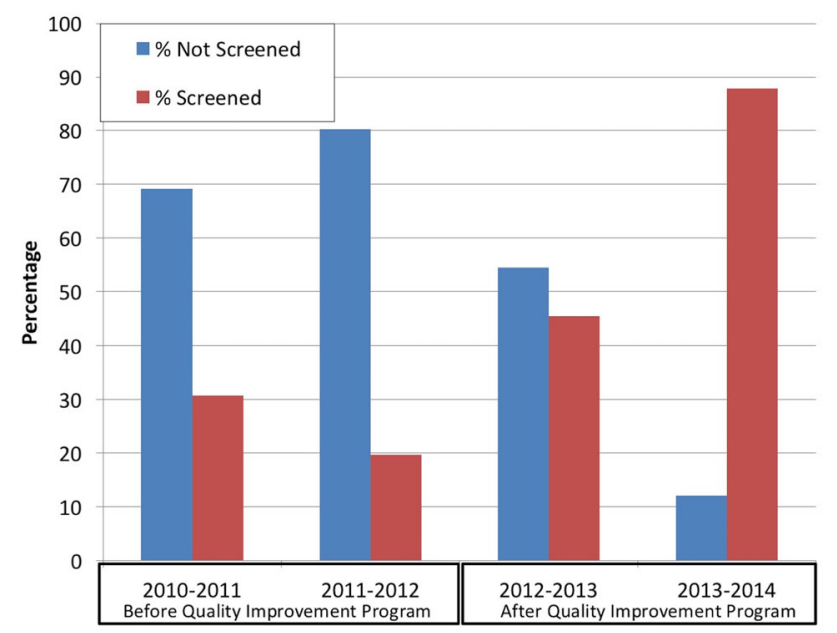

Fig. 1 The percentage of patients with acute hip fractures by year who were screened for low serum vitamin D levels increased after initiation of a quality improvement project from $31 \%$ of patients in Year 1 (20/65; OR, 0.44; 95\% CI, 0.26-0.75) and $20 \%$ of patients in Year $2(12 / 61$; OR, 0.24 ; 95\% CI, $0.13-0.46)$ to $46 \%$ of patients in Year 3 (30/66; OR, 0.83 ; 95\% CI, $0.51-1.35)$, and $88 \%$ of patients in Year 4 (80/91; OR, 7.27; 95\% CI, 3.87-13.7) $(\mathrm{p}<0.001)$. with female patients more likely to be treated in Years 1 and 2 (females treated: $37 \%$ [30/81; OR, $0.59 ; 95 \% \mathrm{CI}$, $0.37-0.92]$ vs males treated: $19 \%$ [8/43; OR, $0.23 ; 95 \% \mathrm{CI}$, $0.11-0.49$ ]; $\mathrm{p}=0.035$ ). This difference was not present, with the numbers available, in Years 3 and 4 (females treated: $66 \%$ [67/101; OR, 1.97; 95\% CI, 1.30-2.98] vs males treated: $61 \%$ [30/49; OR, 1.58; 95\% CI, 0.89-2.81]; $\mathrm{p}=0.540)$.

The proportion of patients who were documented to be taking vitamin D supplementation at their 6-week followup increased after the quality improvement project $(\mathrm{p}<0.001)$ (Fig. 3). The lowest rates were observed in Year $1(12 \% ; 8 /$ 65; 95\% CI, 5\%-23\%) and Year $2(15 \%$; 9/61; 95\% CI,

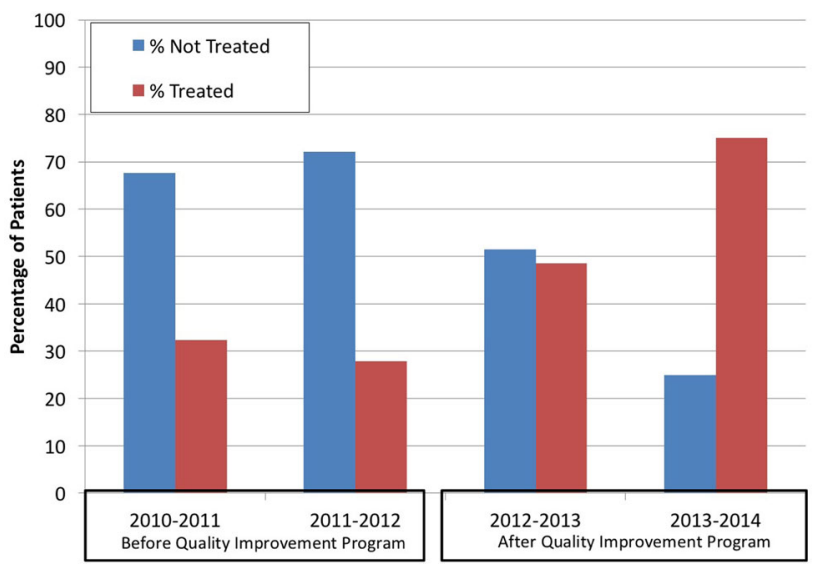

Fig. 2 The percentage of patients with acute hip fractures who were treated for low vitamin D levels was $33 \%$ of patients in Year $1(21 / 63$; OR, 0.5; 95\% CI, 0.30-0.84), 28\% in Year 2 (17/61; OR, 0.39; 95\% CI, 0.22-0.68) and increased to 50\% in Year 3 (32/64; OR, 1.00; 95\% CI, 0.61-1.63), and 76\% in Year 4 (65/86; OR, 3.10; 95\% CI, 1.895.06) $(\mathrm{p}<0.001)$.

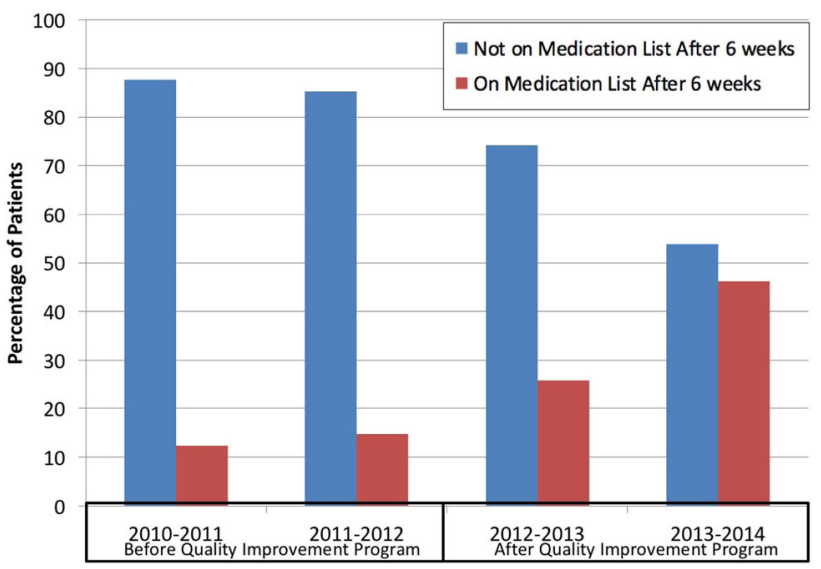

Fig. 3 The percentage of patients who continued to take vitamin D supplementation at least 6 weeks after hospital discharge improved from $12 \%$ in Year $1(8 / 65 ; 95 \%$ CI, 5\%-23\%) and $15 \%$ in Year $2(9 /$ $61 ; 95 \% \mathrm{CI}, 7 \%-26 \%)$ to $26 \%$ in Year 3 (17/66; 95\% CI, 16\%-38\%) and $46 \%$ in Year $4(42 / 91 ; 95 \%$ CI, 36\%-57\%) $(\mathrm{p}<0.001)$. 
$7 \%-26 \%)$. The rate was $26 \%(17 / 66 ; 95 \% \mathrm{CI}, 16-38 \%)$ in Year 3 and improved to $46 \%$ (42/91; 95\% CI, 36-57\%) in Year 4.

\section{Discussion}

Vitamin D insufficiency is a widespread problem in patients with acute hip fractures, leading to increased bone turnover that contributes to fragility fractures [7, 13]. Previous studies have shown that vitamin D supplementation provided a $14 \%$ decrease in the risk of nonvertebral fractures and $19 \%$ reduced risk of falls $[4,5]$. The purpose of this current project was to evaluate a quality improvement initiative at our institution that focused on screening and treating vitamin D insufficiency in patients with acute hip fractures. We observed that the screening and treating rates for low vitamin D improved after initiation of this effort. Additionally, vitamin D was prescribed more frequently at the 6-week followup after this project compared with the 2 years before the project.

Our study should be interpreted in light of several notable limitations. As a retrospective, single-institution investigation, it is unclear whether these findings are representative of and applicable to other hospitals. There was incomplete demographic data, especially during the first 2 years of this program (before implementation of a new electronic medical record system), although this would not affect the recovered laboratory values or medication lists. We relied on electronic medical records and do not have information regarding patient compliance with medication recommendations, either immediately or at followup. With initiatives such as this, there is often a decrease in interest or participation with time. We are unable to comment on the long-term effectiveness of this intervention. In addition, the current project did have a small financial incentive for all residents in the department. We cannot know how effective this project would be without this compensation. Our followup time was 6 weeks after discharge. Adherence to vitamin D supplementation likely wanes with time, and we are not able to determine if our efforts improve longerterm adherence to postdischarge medication. However, we have established standardized hip fracture order sets that include vitamin D testing and treatment, if appropriate, and referral to our outpatient skeletal health clinic.

Multiple authors have advocated for an increased focus on starting vitamin D supplementation in patients with acute hip fractures, and interdisciplinary teams to improve care for these patients [2, 17]. Previously, in a study of 1090 patients with hip fractures, Maier et al. [13] reported that $26.5 \%$ of patients had vitamin D prescribed at the time of discharge, similar to the proportion observed in the current study before our intervention. A previous study showed that osteoporosis may be underdiagnosed in men [15], which may explain the sex-based difference in treatment rates seen before starting our quality improvement program. Given the success of other housestaff quality improvement programs, we selected this model to reach this goal. Lee et al. [11] reported a $46 \%$ cost reduction and decreased rate of Clostridium dificile infection after introduction of a resident-based antimicrobial stewardship program. They used a biweekly audit and checklist program to encourage appropriate antibiotic use. A resident-led initiative resulted in increased adherence to improvements and timeliness in completing discharge summaries [3]. This program used frequent data reporting and discussion of best practices at monthly education meeting. Yu et al. [19] described a trainee-led introduction of radiation dose reporting. They had a single educational meeting, in addition to templated reports, that led to a $92 \%$ rate of reporting radiation dosage for CT scans. Our methods differed from those in these prior studies in that we relied on frequent reminders and quarterly data reports to the residents. All of these prior studies help show the vital role that residents can serve in achieving quality improvement goals related to direct patient care.

Our quality improvement project, while focused on inhospital initiation of vitamin D supplementation, had positive effects that carried over to the 6-week followup. Maier et al. [13] found only $21.5 \%$ of patients were receiving vitamin $\mathrm{D}$ supplementation 6 months after an acute hip fracture. The main reason why patients were not taking supplementation, according to a survey of primary care providers, was that vitamin D was "not mentioned in the discharge letter from acute care" [13]. Giusti et al. [7] prescribed vitamin $\mathrm{D}$ and calcium supplements to all patients after acute hip fracture and found only $36.7 \%$ of patients continued to take these supplements 6 months after discharge. In-hospital initiation of osteoporosis management by an orthopaedic surgeon has been shown to be more effective than relying on initiation of treatment by a primary care provider [14]. Miki et al. [14] reported that 58\% of patients who had osteoporosis treatment started in the hospital continued treatment at 6 months after discharge. Our results are at a shorter endpoint (6 weeks) relative to these other studies, and our supplementation rates, while improved, were still only $46 \%$ in the final year. The factors that determine compliance after discharge remain unclear and future efforts should be directed toward improving long-term adherence to vitamin D supplementation.

A resident-led quality improvement program improved the proportion of patients who were screened and treated for low vitamin D after an acute hip fracture. Orthopaedic surgeons should focus on diagnosing and treating low vitamin D and osteoporosis in this high-risk population. Surgical residents can have an important role in this and 
other efforts as important care providers at academic medical centers. Future studies should evaluate the longterm effect on health and function with appropriate vitamin D supplementation and long-term adherence to supplements prescribed with this program. Finally, a followup in 2 to 3 years to assess whether the current initiative has persisted as part of clinical practice would be valuable, as it is common for compliance with quality improvement initiatives to dwindle with time.

\section{References}

1. Accreditation Council for Graduate Medical Education. ACGME Program Requirements for Graduate Medical Education in Orthopaedic Surgery. Available at: https://www.acgme.org/ Portals/0/PFAssets/ProgramRequirements/260_orthopaedic_ surgery_2016.pdf. Accessed July 14, 2016.

2. American Orthopaedic Association. Leadership in orthopaedics: taking a stand to own the bone. American Orthopaedic Association position paper. J Bone Joint Surg Am. 2005;87:1389-1391.

3. Bischoff K, Goel A, Hollander H, Ranji SR, Mourad M. The Housestaff Incentive Program: improving the timeliness and quality of discharge summaries by engaging residents in quality improvement. BMJ Qual Saf. 2013;22:768-774.

4. Bischoff-Ferrari HA, Dawson-Hughes B, Staehelin HB, Orav JE, Stuck AE, Theiler R, Wong JB, Egli A, Kiel DP, Henschkowski J. Fall prevention with supplemental and active forms of vitamin D: a meta-analysis of randomised controlled trials. BMJ. 2009;339:b3692.

5. Bischoff-Ferrari HA, Willett WC, Orav EJ, Lips P, Meunier PJ, Lyons RA, Flicker L, Wark J, Jackson RD, Cauley JA, Meyer HE, Pfeifer M, Sanders KM, Stähelin HB, Theiler R, DawsonHughes B. A pooled analysis of vitamin D dose requirements for fracture prevention. N Engl J Med. 2012;367:40-49.

6. Boonen S, Rizzoli R, Meunier PJ, Stone M, Nuki G, Syversen U, Lehtonen-Veromaa M, Lips P, Johnell O, Reginster JY. The need for clinical guidance in the use of calcium and vitamin D in the management of osteoporosis: a consensus report. Osteoporos Int. 2004;15:511-519.

7. Giusti A, Barone A, Razzano M, Oliveri M, Pizzonia M, Palummeri E, Pioli G. Persistence with calcium and vitamin D in elderly patients after hip fracture. J Bone Miner Metab. 2009;27:95-100.

8. Han SJ, Saigal R, Rolston JD, Cheng JS, Lau CY, Mistry RI, McDermott MW, Berger MS. Targeted reduction in neurosurgical laboratory utilization: resident-led effort at a single academic institution. J Neurosurg. 2014;120:173-177.

9. Holick MF. Vitamin D deficiency. N Engl J Med. 2007;357:266281.

10. Kanis JA, Johnell O, De Laet C, Johansson H, Oden A, Delmas P, Eisman J, Fujiwara S, Garnero P, Kroger H, McCloskey EV, Mellstrom D, Melton LJ, Pols H, Reeve J, Silman A, Tenenhouse A. A meta-analysis of previous fracture and subsequent fracture risk. Bone. 2004;35:375-382.

11. Lee TC, Frenette C, Jayaraman D, Green L, Pilote L. Antibiotic self-stewardship: trainee-led structured antibiotic time-outs to improve antimicrobial use. Ann Intern Med. 2014;161(10 suppl):S53-S58.

12. Leibson CL, Tosteson AN, Gabriel SE, Ransom JE, Melton LJ. Mortality, disability, and nursing home use for persons with and without hip fracture: a population-based study. J Am Geriatr Soc. 2002;50:1644-1650.

13. Maier S, Sidelnikov E, Dawson-Hughes B, Egli A, Theiler R, Platz A, Staehelin HB, Simmen HP, Meier C, Dick W, Grob D, von Eckardstein A, Bischoff-Ferrari HA. Before and after hip fracture, vitamin D deficiency may not be treated sufficiently. Osteoporos Int. 2013;24:2765-2773.

14. Miki RA, Oetgen ME, Kirk J, Insogna KL, Lindskog DM. Orthopaedic management improves the rate of early osteoporosis treatment after hip fracture: a randomized clinical trial. $J$ Bone Joint Surg Am. 2008;90:2346-2353.

15. Papaioannou A, Kennedy CC, Ioannidis G, Gao Y, Sawka AM, Goltzman D, Tenenhouse A, Pickard L, Olszynski WP, Davison KS, Kaiser S, Josse RG, Kreiger N, Hanley DA, Prior JC, Brown JP, Anastassiades T, Adachi JD; CaMos Research Group. The osteoporosis care gap in men with fragility fractures: the Canadian Multicentre Osteoporosis Study. Osteoporos Int. 2008;19:581-587.

16. Patow CA, Karpovich K, Riesenberg LA, Jaeger J, Rosenfeld JC, Wittenbreer M, Padmore JS. Residents' engagement in quality improvement: a systematic review of the literature. Acad Med. 2009;84:1757-1764.

17. Skedros JG. The orthopaedic surgeon's role in diagnosing and treating patients with osteoporotic fractures: standing discharge orders may be the solution for timely medical care. Osteoporos Int. 2004;15:405-410.

18. Tosi LL, Gliklich R, Kannan K, Koval KJ. The American Orthopaedic Association's "own the bone" initiative to prevent secondary fractures. J Bone Joint Surg Am. 2008;90:163-173.

19. Yu JP, Kansagra AP, Naeger DM, Gould RG, Coakley FV. Template-driven computed tomography radiation dose reporting: implementation of a radiology housestaff quality improvement project. Acad Radiol. 2013;20:769-772. 